\title{
Bir Sivil Toplum Kuruluşunda Bilgi ve Belge Merkezi Örneği Olarak Konrad Adenauer Vakfı ve Projeleri Kütüphanesi
}

\author{
Konrad Adenauer Foundation and Projects Library as the \\ Information and Documentation Center in a Non-government \\ Organization
}

\section{Cüneyt Örkmez **}

\section{$\ddot{O z}$}

Sivil toplum örgütleri, çalışma ve örgütlenme ciddiyetleri ölçüsünde organize olmuş bilgi kullanımına gereksinim duyarlar. Bu örgütler gelişmekte olan demokrasilerin vazgeçilmezleri oldukları gibi, bilgi toplumunun oluşumunda da etkindirler. Konrad Adenauer Vakti, bir sivil toplum kuruluşu olarak iş birliğine girdiği Türk ortakları ile geniş bir etkinlik ala$n$ içerisinde, ülkemizin sosyal, siyasal, ekonomik ve kültürel gelişimine yardımcı çalışmalar yapmakta; çalışmalarını ve etkinliklerini yayın yoluyla bilgi kullanicilarının hizmetine sunmaktadır. Bu makale, Konrad Adenaver Vakfs ve Projeleri Kütüphanesinin oluşumunu ve hizmet sürecini açiklamaktadir.

Anahtar sözcükler: Özel kütüphaneler, Kütüphane tanitımı, Konrad Adenauer Vakfı ve Projeleri Kütüphanesi, Sivil toplum kuruluşlart.

\begin{abstract}
Organised knowledge is needed by the non-governmental organizations at the intersity depending upon the seriosity of their work and organizational structure. These organizations, which are indispensible agencies of growing democracies, are also effective in the emergence of knowledge-based societies. Konrad Adenaver Foundation, within its wide area of collaboration with the Turkish partners for the sake of providing studies to support the social, political, economic and cultural development of our country also aims at informing the end-user about the
\end{abstract}

\footnotetext{
* Kütüphaneci; Konrad Adenauer Vakfı ve Projeleri Kütüphanesi (corkmez@yahoo.com).
} 
foundation's studies by means publications. The present study resumes the establishment of the Library of Konrad Adenauer Foundation and Projects and its processes of providing user services.

Keywords: Special libraries, Library publicity, Konrad Adenauer Foundation and Project Library, Non-governmental organizations.

\section{Giriş}

Bilgi, bilgi toplumunun yapı taşı ise, onun gerektiği gibi kullanımı, kullanımının yaygınlaştırılması ve kolaylaştırılması aşamalarında bilgi ve belge merkezleri ile çalışanlarının özel bir yeri ve görevi vardır. Bilgi ve belge merkezleri, bilgiye gereksinim duyulan her yerde, ilgi yoğunluğunun yanı sıra yeterli istek ve çaba sonucu bir uzman yardımı ile kurulabilir. Şüphesiz her kurum böyle bir merkeze intiyaç duymayabilir. Ancak etkin bir sivil toplum kuruluşunun, bir bilgi ve belge merkezine sahip olması, ilgili olduğu alanlara dönük çaışmalar sonucu ürettiği bilginin organizasyonunu sağladığı gibi bunu diğer bilgi kullanıcılarının hizmetine sunması anlamına da gelmektedir. Güvenilir, etkin ve üretken bir kurum şeffaf bir ortamda, ürettiklerini cesaretle paylaşabilmelidir. Sivil toplum örgütleri demokratik işlevleri gereği katılım düzeyini yükseltme, demokratik tutumların geliştirilmesi, çıkarlar ve taleplerin şekillendirilmesi, kutuplaşmaların yumuşatılması, siyasal partilerin demokratikleştiriłmesi, bilgiyi toplumun geniş kesimlerine yayma, yeni fikirlerin gelişmesini paylaşımını sağlama ve siyasal sistemin halka karşı sorumiuluğunu artırmayı amaçlayan kurumlardır. Bu tanımlama, bir anlamda çağdaş bilgi toplumunun oluşabilmesinde, sivil toplum kuruluşlarına düşen görevi de açıklamaktadır. Konrad Adenauer Vakfı ve Projeleri Kütüphanesi, bağlı olduğu sivil toplum kuruluşłarının görev ve sorumlulukları çerçevesinde kurulmuş bir bilgi ve belge merkezidir.

\section{Konrad Adenauer Vakfı ve Projeleri}

Konrad Adenauer Vakfı, bağımsız ve kamu yararına çalışan bir siyasi vakıf olup merkezi Almanya'dadır. 2.Dünya Savaşı sonrası Almanya'nın özgür ve çağdaş ülkeler ailesine girmesinde büyük emeği olan Almanya Federal Cumhuriyeti'nin ilk şansölyesi Konrad Adenauer adına kurulmuştur. Vakıf, 40 yıl- 
dan bu yana uluslararası işbirliğine yönelik çalışmalarına devam etmekte ve 84 ülkede yaklaşık 230 projeye danışmanlık yapmaktadır. 1983 yılından itibaren Türkiye'de çalışmalar yapan Konrad Adenauer Vakfı, çalışmalarını ortakları olan Türk kuruluşları ile birlikte sürdürmektedir. Bu kuruluşlar şunlardir;

- Türk Demokrasi Vakfı (TDV),

- Türkiye Orta Ölçekli Sanayici ve Serbest Meslek Mensupları ve Yöneticileri Vakfı (TOSYÖV),

- Türk Belediyeler Birliği Derneği (TBBD)

- Türkiye Gazeteciler Cemiyeti (TGC)

- Karadeniz Ekonomik İşbirliği Daimi Sekreteryası (KEiB)

\section{Neden Konrad Adenauer Vakfı ve Projeleri Kütüphanesi}

Konrad Adenauer Vakfı'nın adı geçen kuruluşlarla birlikte yürüttüğü projeler geniş bir alanda bilgi ve deneyimlerin paylaşımı anlamına gelmektedir. Bu bilgi ve deneyimler, (konferanslar, toplantı, kongre vb.) sosyal etkinliklerle katııımı kitlelerle paylaşılmakta ve yapılan çalışmalar kayıt ortamları yardımı ile bilgi kaynaklarına dönüştürülmektedir. Vakfın bugüne değin Türkiye'de sadece kitap olarak yayımlanmış 100 'e yakın yayını, ortaklaşa çalışılan kurumlarla birlikte yayımladığı çok sayıda bilgi kaynağı vardır. Ayrıca vakıf merkezi ve diğer ülkelerdeki temsilçiliklerde de çok sayıda bilgi kaynağı oluşturulmaktadır. Konrad Adenauer Vakfı ve çalışma ortağı olan diğer sivil toplum örgütleri, etkinlik süreçlerinde birçok bilgi ve danışma kaynağına ihtiyaç duymaktadırlar. Çalışmaları için gerekli tüm bilginin kullanımı ve paylaşımı süreci içerisinde oluşan bilgi ve belgenin organizasyonu, Konrad Adenauer Vakfı ve Projeleri Kütüphanessi'nin oluşumunu sağlamışır.

\section{Koleksiyon ve Sağlama}

Kütüphane, Konrad Adenauer Vakfı (KAV), Türk Demokrasi Vakfı (TDV) ve Türk Belediyeler Birliği Derneği (TBBD) ile aynı binada, bu kuruluşların ortak bilgi ve belge merkezi olarak hizmet vermektedir. Ayrıca, daha önce aynı bi- 
nada olan ancak mekan darlığı nedeniyle başka yere taşınan TOSYÖV'nın da geçmişe dönük tüm bilgi kaynaklarını bünyesinde bulundurmaktadır.

Koleksiyon, yaklaşık 6000 kitap, aboneliği devam eden 100 süreli yayın ve etkinliklere ait ses kayıtlarını içeren kasetlerden oluşmaktadır. Adı geçen kuruluşların yapmış oldukları çalışmalar sırasında kendiliğinden oluşan kaynak birikiminin yanı sıra koleksiyonun satın alma, bağış ve değişimi ile zenginleştirilmesine çalışılmaktadır. Vakıf ve ortak kuruluşların çalışanları ve okuyucu tercihleri dikkate alınarak gereksinim duyulan bilgi kaynakları yayıncı kuruluşlardan bağłş yoluyla sağlanabilmektedir. Kütüphanede yayın değişimi başarı ile uygulanmaktadır. Konrad Adenauer Vakfı ve Projeleri aynı zamanda birer yayıncı olduklarından kamu yararına sunulmak üzere birçok kitabın yayımını ve dağııımını gerçekleştirmektedir. Üretilen nitelikli bilgı kaynakları, diğer sivil toplum kuruluşları ile resmi ve özel kurumların da ilgisini çekmekte, bu da yayınların karşılıkıı olarak değişimini kolaylaşıırmaktadır. Bir diğer katkı ise Vakıf ve ortak sivil toplum kuruluşları çalışanlarının yaptıkları araştırmalar esnasında sağladıkları ve kullandıkları kaynakların güncel kullanımları bittiğinde kütüphane koleksiyonuna dahil edilmesidir.

Kütüphanenin Vakıf bütçesinden ayrılan bir bütçesi vardır. Bu bütçeden proje çalışmaları için gereksinim duyulan konular öncelikli olmak üzere satın alma yoluyla da koleksiyon zenginleştirilmektedir.

\section{Kaynak Seçimi}

Sosyal bilimlere yönelik özel bir araştırma küłüphanesi olma niteliği, kaynak seçiminde dikkatli ve titiz davranmayı zorunlu hale getirmektedir. Sosyal bilimler ve ilgili alanlarında yayınlanmış birçok kaynak da kullanıcıların ilgisini çekmektedir. Ancak ilgili her kaynağın sağlanması, gerek mekan gerekse bilgi ve belge düzenlemesi açısından bu ölçekte bir kütüphanenin kaldıramayacağı bir yük anlamına gelmektedir. Bu nedenle, koleksiyon geliştirme sürecinde, Vakfın ve ortak çalışma yaptığı kuruluşların konularına belli bir mesafeden bakılmaktadır.

Konrad Adenauer Vakfı'nın bir Alman kuruluşu olmasından dolayı Almanya ve Türk-Aiman ilişkileri, AB ve diğer uluslararası ilişkilerle ilgili konular kütüphane için önemlidir. Bunun dışında yerel yönetimler ve KOBi'ler, demok- 
rasi ve demokrasi kültürü, siyasal, ekonomik ve kültürel konular, sivil toplum, hukuk devleti ve insan hakları ile ilgili açıımlar, medya ve eğitim diğer önemli sayılabilecek alanları oluşturmaktadır.

\section{Personel}

Kütüphane, 1995 yıında bir küłüphaneci gözetiminde geçici yardımcı elemanlar istihdam edilerek bir yıl içinde kuruluşu tamamlanmış ve hizmete sunulmuştur. Halen görev yapan tek kütüphaneci, 1996 yılından itibaren çalışmalarını sürdürmektedir. Bu ölçekte bir bilgi ve belge merkezinin, kütüphanecilik biliminin kural ve yöntemlerine uygun bir şekilde, bir kütüphane uzmanı tarafından yönetilmesi, geliştirilmesi ve hizmetlerini sürdürülmesinde zaman zaman zorluklar yaşanabilmektedir. Ancak kütüphanecinin hem kurucu olmaSı, hem de uzun süredir burada çalışıyor olması, belli bir güdüleme ve verimlilik yaratmış, böylece kütüphane, işlevsel bir bilgi ve belge merkezi olarak gelişimine devam edebilmiştir.

Uius|ararası ilişkiler alanında öğrenim gören öğrenciler için Konrad Adenauer Vakfı bir staj yeri nitelığindedir. Bu öğrenciler, stajlarının büyük bölümünü kendi alanlarında birçok bilgi kaynağını barındıran yer olan kütüphanede yapmaktadırlar. Böylece kütüphane, burada staj yapan gönüllü öğrencilere hem bir bilgi ve belge merkezinin çalışması hakkında fikir vermekte, hem de yaşamları boyunca gereksinim duyacakları bilginin düzenlemesi işlemini anlamalarına yardımcı olmaktadır. Ayrıca bu stajlar, farklı alanlarda öğrenim gören öğrencilerin, bilgi okuryazarlığı becerisi kazanmalarını teşvik eden bir uygulama olarak değerlendirilebilir.

\section{Teknik Hizmetler}

Kütüphanede Dewey Onlu Sınıflama sistemine göre sınıflandırılmakta ve kaynaklar açık raf sistemi ile kullanıcıya sunulmaktadır. Kütüphanenin kuruluş yıllarında kart katalog düzenlenmiş, 1998 yılından itibaren UNICEF'den bağış olarak sağlanan CDS/ISIS kütüphane programı kullanıtmaya başlanmıştır. Halen veri girişleri ve bilgi erişimi bu programla yapılmaktadır. 
Konrad Adenauer Vakfı'nın Almanya'da ve diğer ülkelerde yayımladığı Almanca ve çeşitli dillerdeki dergiler, bağış olarak gelen veya abone olunan süreli yayınlar, ortaklaşa çalışmalar yürütülen kuruluşların dergileri, geçmiş yıtlara ait arşivleri ile birlikte süreli yayın koleksiyonunu meydana getirmektedir.

Kütüphaneye, beş günlük gazete düzenli olarak ulaştırıłmaktadır. Bu gazeteler ve zaman zaman sağlanan diğer gazeteler için 1997 yılından bu yana bir arşiv çalışması yapılmaktadır. Başlangıçta oldukça fazla olan takip konuları bugün azaltılarak daha dar bir alana yönelik bir şekle dönüşmüştür. Özellikle Ałmanya ile ilgili konular için gazete arşivi çalışmasının geliştirilmesi planlanmaktadır.

\section{Okuyucu ve Bilgi Hizmetleri}

Kütüphane, bir salonda açık raf sistemi ile hizmet verdiğinden okuyucu, tüm kaynaklara kolayca erişebilmektedir. Katalog sorgulama sistemlerinin kullanımı ve bilgiye erişim için her türlü danışmanlık hizmeti, kütüphane sorumlusu tarafından sunuımaktadır. Kullanıcının aradığı bilgiyi tanımlaması ile başlayan yararlanma sürecinde, kullanıcı ve kütüphaneci ortak çalışması ile mümkün olduğunca uygun ve yeterli sayıda bilgi kaynağına erişim amaçlanmaktadır.

Özel kütüphane olarak belli konularda kullanıcılara bilgi ve belge vermeyi amaçladığı için her zaman bilgi kaynaklarının yerinde bulunması yararlı görüłmüştür. Ödünç alınan bilgi kaynağına bu süre içinde diğer kullanıcıların erişememesi ve özellikle kullanıcıların büyük bir bölümünün şehir dışından gelmesi böyle bir özel kütüphane için ödünç verme işlemini sakıncalı hale getirmiştir. Çok özel durumlar dışında, kaynaklardan kütüphane içinde yararlandırılmakta ve fotokopi almaları sağlamaktadır. Kütüphane aracılığıyla, Vakła ait yayınlardan mevcut olanlar, isteyenlere ücretsiz olarak hediye edilmektedir.

\section{Sonuç}

Konrad Adenauer Vakfı ve Projeleri Kütüphanesi, bağlı ve ilgili olduğu sivił toplum kuruluşlarının çalışma süreçlerine yararlı olacak bilgi ve belgenin yö- 
netimini sağlayarak yedi yıldır çalışmalarına devam etmektedir. Kütüphanenin gelecekteki hedefi, elektronik bilgi hizmetlerindeki hızlı gelişmelere uygun biçimde, daha kolay ulaşılan ve daha çok kullanılan bir özel kütüphane olarak çalışmalarına devam etmektir.

\section{Kaynakça}

Konrad Adenauer Vakfı (2002). Devlet ve sivil toplum bağlaminda halk katsIImcıllğı ve sivil toplum kuruluşları. Ankara: Konrad Adenauer Vakfı.

Konrad Adenauer Vakfı (2002). Tanıtım kitapçı̆ı. Ankara: Konrad Adenauer Vakfı.

Tosun, G. E. (2001). Demokratikleşme perspektifinde devlet-sivil toplum ilişkisi (Türkiye Örneği). İstanbul: Alfa Yayınları. 